\title{
COMPARATIVE STUDY OF MANUAL VERSUS AUTOMATED BIOMETRY ON REFRACTIVE OUTCOME OF CATARACT SURGERY
}

\author{
Santosh Singh Patel1, Rajesh Kumar Sahu², A. K. Chandrakar³, M. L. Garg ${ }^{4}$ Reshu Malhotra ${ }^{5}$
}

${ }^{1}$ Associate Professor, Department of Ophthalmology, Pt. JNM Medical College and Dr. Bhim Rao Ambedkar Hospital, Raipur, Chhattisgarh, India.

${ }^{2}$ Assistant Professor, Department of Ophthalmology, Pt. JNM Medical College and Dr. Bhim Rao Ambedkar Hospital, Raipur, Chhattisgarh, India.

${ }^{3}$ Director and Professor, Department of Ophthalmology, Pt. JNM Medical College and Dr. Bhim Rao Ambedkar Hospital, Raipur, Chhattisgarh, India.

${ }^{4}$ Professor, Department of Ophthalmology, Pt. JNM Medical College and Dr. Bhim Rao Ambedkar Hospital, Raipur, Chhattisgarh, India. ${ }^{5}$ Assistant Professor, Department of Ophthalmology, Pt. JNM Medical College and Dr. Bhim Rao Ambedkar Hospital, Raipur, Chhattisgarh, India.

\begin{abstract}
BACKGROUND
Intraocular Lens (IOL) power calculation is the most important step to achieve best refractive outcome in cataract surgery. Various studies had revealed that about $54 \%$ of the error in predicted refraction occurred due to inaccuracy in axial length measurement alone. Therefore, axial length measurement is the most important step to minimise these errors.

The aim of this study was to compare IOL power calculation using a manual method (Applanation ultrasound A-Scan and Keratometry) with the automated method (Optical biometry).
\end{abstract}

\section{MATERIALS AND METHODS}

It was a prospective, comparative study. In this study, 200 eyes of 196 patients were analysed in the Department of Ophthalmology. Each eye underwent measurement by both methods, with manual method (Applanation Ultrasound A-Scan and manual Keratometer) and with automated optical biometry. Axial length and Keratometric readings were obtained and IOL power calculation was done by both the methods. Patient underwent clear corneal phacoemulsification cataract surgery within the IOL implantation in all the cases, then postoperative autorefraction was noted in all cases in follow-ups.

\section{RESULTS}

The Mean Axial Length calculated by optical A scan was $23.02 \pm 1.00 \mathrm{~mm}$ and by ultrasound A scan was $22.93 \pm 1.03 \mathrm{~mm}$. The mean difference in axial length between optical system and Ultrasound A scan was $0.087 \pm 0.039 \mathrm{~mm}$, which is statistically not significant ( $p$ value 0.19). However, differences in axial length measurement were more when compared, for short eyes, by two devices. After analysis of Bland-Altman plot. All differences were within two standard deviations ( $95 \%$ confidence level) from mean differences $(0.0869 \pm 0.038 \mathrm{~mm}$, i.e. between $0.0096 \mathrm{~mm}$ and $0.1641 \mathrm{~mm})$. The regression line between the two methods, Pearson's correlation coefficient ' $r$ ' is 0.999 , which evaluates excellent agreement of axial length measurement between two methods. The differences in mean IOL power between automated method and manual method was $0.43 \pm 0.38 \mathrm{D}$, which was statistically and clinically insignificant ( $\mathrm{p}$ value 0.09).

\section{CONCLUSION}

To measure axial length and IOL power, optical biometry is very precise and interchangeable with ultrasound method. Optical biometry in short eyes gives better result in axial length measurement as compared to ultrasound A-scan.

\section{KEY WORDS}

A-Scan, Keratometry, Optical Biometry, IOL Calculation.

HOW TO CITE THIS ARTICLE: Patel SS, Sahu RK, Chandrakar AK, et al. Comparative study of manual versus automated biometry on refractive outcome of cataract surgery. J. Evolution Med. Dent. Sci. 2018;7(45):4893-4895, DOI: 10.14260/jemds/2018/1089

\section{BACKGROUND}

Cataract surgery has been changed from a purely surgical procedure to one of the refractive or "vision correcting" procedure.

'Financial or Other Competing Interest': None.

Submission 02-06-2018, Peer Review 17-10-2018,

Acceptance 25-10-2018, Published 05-11-2018.

Corresponding Author:

Rajesh Kumar Sahu,

Qu. No. F/16,

Medical College Campus,

Pt. JNM Medical College,

Raipur-492001, Chhattisgarh, India.

E-mail: rajeshk2003@gmail.com

DOI: $10.14260 /$ jemds/2018/1089
IOL power calculation is the most critical step to achieve desired refractive outcome. Moreover, for accurate IOL power calculation axial length measurements, keratometric reading and IOL power calculation formula should be accurate.[1] Various studies had revealed that about $54 \%$ of the error in predicted refraction occurred due to inaccuracy in axial length measurement alone. Therefore, axial length measurement is the most important step to minimise these errors.[2] About 2.35 D error in IOL power calculation occurred in $1 \mathrm{~mm}$ error in axial length measurement. [3]

Over a decade ago, optical biometer was introduced into clinical practice. To determine the distance between interferences, LASER is used in optical biometry. It works by interference phenomenon between reflected signal and reference signal. For accurate calculation of axial length, 
optical biometry is becoming popular nowadays as it is easy to use, fast, operator independent and contact free method. The Lenstar LS 900 (Haag-Streit, USA) is optical Low Coherence Reflectometry (LCOR) based and uses a $820 \mathrm{~nm}$ super luminescent diode.[4] In developed nations, accurate and fast methods of measurement of axial length now routinely available due to recent advances in techniques. Whereas in developing nations ophthalmologists continue to rely on applanation and immersion ultrasound biometry in clinical consultation. But skilled doctors or technicians can usually obtain accurate Axial Length and IOL power measurements using these methods.

\section{MATERIALS AND METHODS}

In this prospective study, 196 consecutive patients of cataract (200 eyes) were enrolled in the Department of Ophthalmology. Each patient underwent axial length measurement by both applanation ultrasound A scan and optical low coherence reflectometry (By Lenstar). Keratometric readings were taken from Lenstar and Bausch Lomb manual keratometer. IOL power calculated using IOL calculation formula like SRK/T, Hoffer-Q and Holladay formula as per length of eyes. According to axial length of eye three groups were made; short $(<22 \mathrm{~mm})$; normal $(22-24.50$ $\mathrm{mm}$ ); and long (>24.50 mm). All the data were collected, and statistical calculation was done using Microsoft Office Excel (2007). The mean, Standard Deviation (SD), standard error of the mean, Bland-Altman plot, Pearson's correlation coefficient (r) calculated. With the help of linear regression, correlations were assessed between two different methods. Student ' $t$ ' test was used to compare data. P-value of less than 0.05 was statistically significant. Scatter diagram and Pearson's correlation coefficient were used to analyse the correlation between the axial length and IOL power calculation by optical A scan biometry and manual A-Scan ultrasound. Bland-Altman plot were used for the analysis of agreement between graph of the ratios and readings measured by the two methods plotted against the means for the pairs of measurements. The upper and lower limits are connected with horizontal straight lines for the $95 \%$ confidence interval.

\section{RESULTS}

The study sample comprised of 196 consecutive patients (200 eyes), of which 82 were females and 114 were males. The majority of patients in the study were age group 40 - 59 years, i.e. 61 Males (52.5\% of total male), 49 Females (58.2\% of total female) (Table 1 ).

Both eyes of 4 patients were included in the study. Mean age of patients was $48.47 \pm 12.98$ years (Range 14 - 78 years). The mean axial length calculated by optical system (Lenstar) was $23.02 \pm 1.00 \mathrm{~mm}$ (Range $19.91-27.27 \mathrm{~mm}$ ) and by ultrasound A scan was $22.93 \pm 1.03 \mathrm{~mm}$ (Range $19.74-27.21$ $\mathrm{mm}$ ) (Table 2). The Mean Keratometric reading for optical system (Lenstar) was $44.75 \pm 1.70 \mathrm{D}$ and for manual method by Bausch and Lomb Keratometer was $44.52 \pm 1.66$ D.

\begin{tabular}{|c|c|c|c|}
\hline Sl. No. & Age Groups (In Years) & Male & Female \\
\hline 1 & $<20$ & $5(4.3 \%)$ & $2(2.3 \%)$ \\
2 & $20-29$ & $1(0.8 \%)$ & $2(2.3 \%)$ \\
3 & $30-39$ & $24(20.6 \%)$ & $18(21.4 \%)$ \\
4 & $40-49$ & $31(26.7 \%)$ & $26(30.9 \%)$ \\
5 & $50-59$ & $30(25.8 \%)$ & $23(27.3 \%)$ \\
6 & $60-69$ & $19(16.3 \%)$ & $11(13 \%)$ \\
7 & $>70$ & $6(5.1 \%)$ & $2(2.3 \%)$ \\
\multicolumn{3}{|c|}{ Table 1. Demographic Profile in the Study } \\
\hline \multicolumn{3}{|c}{} \\
\hline
\end{tabular}

\begin{tabular}{|c|c|c|c|}
\hline Sl. & $\begin{array}{c}\text { Axial } \\
\text { Length } \\
\text { (mm) }\end{array}$ & $\begin{array}{c}\text { Mean Optical } \\
\text { Length by } \\
\text { Lenstar } \\
\text { (mm) }\end{array}$ & $\begin{array}{c}\text { Mean } \\
\text { Ultrasound } \\
\text { Length } \\
\text { (mm) }\end{array}$ \\
1. & (22 (Hypermetropic) & 21.54 & 21.39 \\
2. & $22-24.5$ (Emmetropic) & 23.06 & 22.98 \\
3. & $>24.5$ (Myopic) & 25.79 & 25.73 \\
\hline
\end{tabular}

Table 2. Comparison of Axial Length with Ultrasound A Scan and Optical A Scan

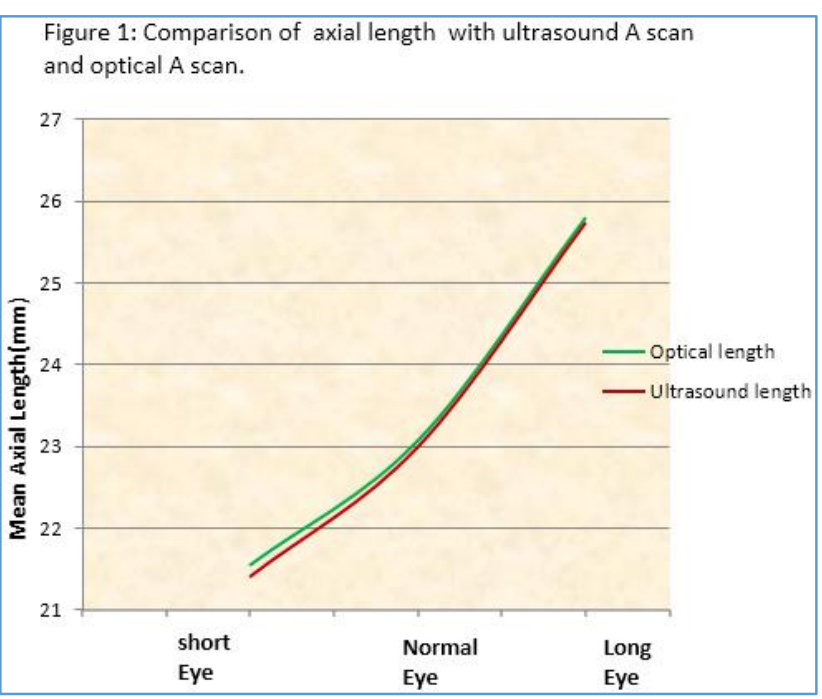

In the Graph (Figure 1) measurement by ultrasound $\mathrm{A}$ scan and optical biometry are stratified according to axial length. The differences in the mean axial length by the two methods are statistically non-significant; however, differences in the measurement are more for short eyes.

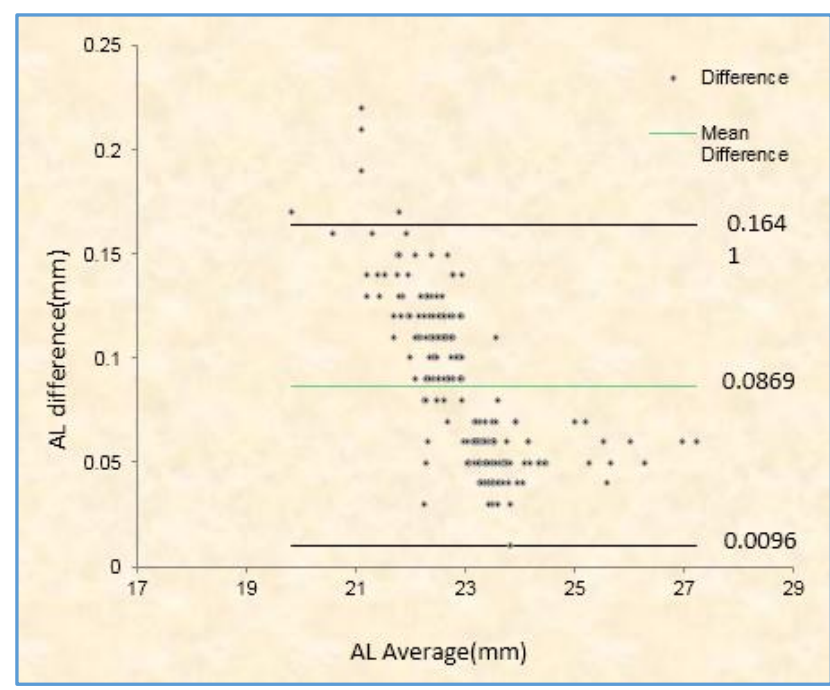

Figure 2. Bland-Altman Plot of the Agreement in Axial Length with Ultrasound A Scan and Optical A Scan 
The above Fig. indicates that $95 \%$ of all differences were within two standard deviations from mean differences $(0.0869 \pm 0.038 \mathrm{~mm}$, i.e. between $0.0096 \mathrm{~mm}$ and $0.1641 \mathrm{~mm})$.

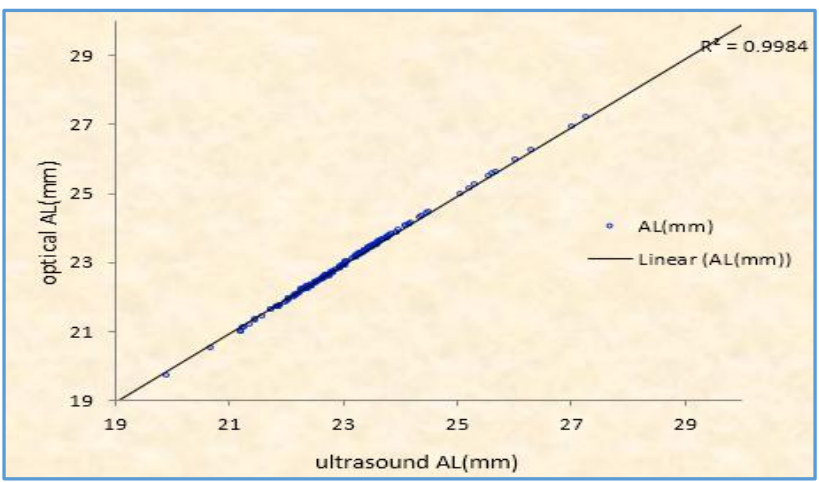

Figure 3. Regression Line between Axial Length Measurement between Ultrasound A Scan and Optical A Scan

In the Graph (Figure 3) Pearson's correlation coefficient ' $r$ ' is 0.999 , which denotes strong correlation of axial length between optical system and ultrasound A scan.

\section{DISCUSSION}

A strong agreement between different methods is required, so that it can be used alternatively.[5] The Mean difference in axial length of optical system (Lenstar) and Ultrasound A scan was $0.087 \pm 0.039 \mathrm{~mm}$, which is statistically insignificant ( $\mathrm{p}$ value $=0.19)$. However, differences in axial length measurement were more when compared for hypermetropic (Short eyes) by two devices (Figure 1). The differences in mean IOL power between automated method and manual method was $0.43 \pm 0.38 \mathrm{D}$, which is statistically and clinically insignificant $(p$ value $=0.09$ ). The Mean post-operative autorefraction (Spherical equivalent) was $0.39 \pm 0.61 \mathrm{D}$. The Mean post-operative autorefraction in hypermetropic, emmetropic and myopic eyes were $0.39 \pm 0.70 \mathrm{D}, 0.38 \pm 0.61 \mathrm{D}$ and $0.35 \pm 0.52 \mathrm{D}$ respectively. No clinically significant differences were found when these findings were compared with mean post-operative refraction. The Bland-Altman plots (Fig. 2) $95 \%$ of all differences were within two standard deviations from mean differences $(0.087 \pm 0.039 \mathrm{~mm})$ that showed good relationship between two instruments. A difference of $0.087 \mathrm{~mm}$ converted to $0.21 \mathrm{D}$, which is statistically and clinically insignificant. In our study, these differences were more when comparing measurements between instruments for small eyes, whereas the difference was not significant when compared with normal to long eyes.

The Mean difference calculated in axial length between optical system (Lenstar) and Ultrasound A scan was $0.087 \pm 0.039 \mathrm{~mm}$, which was statistically and clinically insignificant. These findings are similar to study done by
Chiseliţă D et al 2011,[6] Salouti R et al 2011[7] and Nakhli et al 2014.[8]

\section{CONCLUSION}

In our study, there is no clinical difference in axial length measurement done by both optical biometry (Lenstar) and ultrasound A scan. Optical biometry in hypermetropic eyes gives better result in axial length measurement as compared to ultrasound A scan. Although, IOL power predicted by both Manual method and Automated method has no clinical difference in our study, Automated method gives more consistent result in eyes with different axial length. Consistent results were obtained by both the methods, because all the measurements were done by a 5-year experienced single ophthalmologist. Because of such experienced hand, we have got statistically insignificant difference in both the methods. Advantage of Automated method are fast measurement, non-contact technique, better patient coordination and comfort, operator independent, good for hypermetropic and myopic patient. But it also has disadvantages. It is not useful in dense media opacities like corneal scar, vitreous haemorrhage, mature cataract and thick PSC plaque and has high cost.

\section{REFERENCES}

[1] Drexler W, Findl O, Menapace R, et al. Partial coherence interferometry: a novel approach to biometry in cataract surgery. Am J Ophthalmol 1998;126(4):524-34.

[2] Findl 0. Biometry and intraocular lens power calculation. Curr Opin Ophthalmol 2005;16(1):61-4.

[3] Atebara NH. 2011-2012 Basic and Clinical Science Course, Section 3: clinical optics. American Academy of Ophthalmology 2011: p. 211-23.

[4] Buckhurst PJ, Wolffsohn JS, Shah S, et al. A new optical low coherence reflectometry device for ocular biometry in cataract patients. The British Journal of Ophthalmology 2009;93(7):949-53.

[5] Kottner J, Audige L, Brorson S, et al. Guidelines for Reporting Reliability and Agreement Studies (GRRAS) Int J Nurs Stud 2011;48(6):661-71.

[6] Chiseliță D, Cantemir A, Gălățanu C, et al. Comparison of two new optical biometry devices with an ultrasonic immersion biometer. Oftalmologia 2011;55(4):104-10.

[7] Salouti R, Nowroozzadeh MH, Zamani M, et al. Comparison of the ultrasonographic method with 2 partial coherence interferometry methods for intraocular lens power calculation. Optometry 2011;82(3):140-7.

[8] Nakhli FR. Comparison of optical biometry and applanation ultrasound measurements of the axial length of the eye. Saudi Journal of Ophthalmology 2014;28(4):287-91. 